\title{
An internet-based emotion regulation intervention versus no intervention for nonsuicidal self-injury in adolescents: study protocol for a feasibility trial
}

Britt Morthorst ${ }^{1 *}$, Lotte Rubæk ${ }^{2}$, Jane Lindschou ${ }^{3}$, Janus Christian Jakobsen ${ }^{3,4}$, Christian Gluud ${ }^{3}$, Johan Bjureberg ${ }^{5}$, Clara Hellner ${ }^{5}$, Bo Møhl ${ }^{6}$ and Anne Katrine Pagsberg ${ }^{1}$

\begin{abstract}
Background: Non-suicidal self-injury (NSSI) has gained increased attention in recent years due to increased prevalence, especially among adolescents. Evidence-based interventions for NSSI are sparse. Emotion regulation individual therapy for adolescents (ERITA) is an online intervention that needs investigation. Non-randomised studies suggest ERITA improves emotion regulations skills and reduces NSSI frequency. Before conducting a large pragmatic randomised clinical trial, we aim to investigate the feasibility of ERITA in Denmark.

Methods: A randomised, parallel group feasibility trial comparing ERITA as add on to treatment as usual versus treatment as usual in 30 adolescents age 13-17 years with recurrent NSSI referred to outpatient clinics in The Child and Adolescent Mental Health Services in the Capital Region of Denmark. Feasibility outcomes are (1) completion of follow-up, (2) the fraction of eligible participants who consent to inclusion and randomisation and (3) compliance with the intervention. Clinical outcomes such as self-injury frequency and the ability to regulate emotions will be investigated exploratorily.

Discussion: Internet-based interventions are assumed to be appealing to adolescents by being easily accessible and easy to navigate by tech natives. Disclosure of self-injury behaviour may be facilitated by an online intervention. The evidence for self-injury specific treatment needs to be extended but prior to a large clinical trial, the feasibility of methods and procedures must be assessed.
\end{abstract}

Trial registration: ClinicalTrials.Gov Identifier: NCT04243603.

Keywords: Non-suicidal self-injury, Emotion regulation individual therapy for adolescents (ERITA), Internet-based intervention, Randomised feasibility trial

* Correspondence: britt.reuter.morthorst@regionh.dk

${ }^{1}$ Research Unit, Child and Adolescent Mental Health Services, The Capital Region of Denmark, Gentofte Hospitalsvej 15, 2900 Hellerup, Denmark

Full list of author information is available at the end of the article

(c) The Author(s). 2021 Open Access This article is licensed under a Creative Commons Attribution 4.0 International License, which permits use, sharing, adaptation, distribution and reproduction in any medium or format, as long as you give appropriate credit to the original author(s) and the source, provide a link to the Creative Commons licence, and indicate if changes were made. The images or other third party material in this article are included in the article's Creative Commons licence, unless indicated otherwise in a credit line to the material. If material is not included in the article's Creative Commons licence and your intended use is not permitted by statutory regulation or exceeds the permitted use, you will need to obtain permission directly from the copyright holder. To view a copy of this licence, visit http://creativecommons.org/licenses/by/4.0/. The Creative Commons Public Domain Dedication waiver (http://creativecommons.org/publicdomain/zero/1.0/) applies to the data made available in this article, unless otherwise stated in a credit line to the data. 


\section{Background}

Non-suicidal self-injury (NSSI) has gained increased research attention in recent years since it is a widespread phenomenon across vulnerable groups often with severely damaging behaviours with or without further distinct psychopathology, especially among adolescents. NSSI prevalence and incidence are difficult to estimate due to highly heterogeneous studies, particularly in nonclinical samples [1]; however, an overall prevalence of $17 \%$ among adolescents has been found in recent metaanalyses [2, 3]. Prevalence in community surveys are associated with great underreporting [2], and hidden numbers are referred to as the 'bottom of the iceberg' [4]. A prevalence of $33 \%$ has been observed in a community sample of 15-17-year-old Scandinavian teenagers having self-injured at least once the last year, whist $41 \%$ of these did so repeatedly ( $>11$ episodes the last year) [5]. A lifetime prevalence of $15 \%$ has been shown in US college students following a web-based wellbeing survey [6]. Likewise, incidence rates of NSSI are not easily estimated. A systematic review investigating the longitudinal course of NSSI and deliberate self-harm more broadly, included 32 cohort studies (69\% on NSSI exclusively ( $n$ $=969,197), 75 \%$ in community samples) and one of the main findings was that NSSI is a fluctuating behaviour difficult to assess [7]. A neutral NSSI course was suggested, however, with an observed increase in young adolescence and a decrease in late adolescence or young adulthood [7]. Studies investigating psychiatric populations of youth have shown estimates between 50 and $75 \%$ of patients engaging in self-injurious behaviour, especially in youth with emotional dysregulation and instability in relationships $[8,9]$. In general, psychosocial stressors like hopelessness [10], depressive symptoms [7], sexual dysphoria [11], peer victimization [12], and family dysfunctional aspects are risk factors associated with NSSI [13]. Gender differences exist within the NSSI phenomenon, with more girls injuring themselves than boys $[6,7,14]$. NSSI is a risk factor for adverse outcomes in young people $[15,16]$, among them suicidal behaviour [17-19] and suicide [20, 21]. Since this behaviour is mainly observed during adolescence, researchers have hypothesized that trauma and childhood maltreatment are associated with increased risk for NSSI [22-24]. Perceived low social family and peer support and lack of persons from which to seek advice are factors reported by youth engaging in repeated NSSI $[25,26]$.

Why do so many young people self-injure? NSSI functions are described in the model of Nock and Prinstein as a distinction between intrapersonal (i.e. reinforced by oneself; e.g. emotion regulation) and interpersonal properties (i.e. reinforced by others; e.g. attention or communication) [27]. Most young people engaging in NSSI state intrapersonal functions to be the most prominent function, whilst interpersonal functions are less frequently stated [28]. Difficulty in emotion regulation has been investigated in a meta-analysis, which found that more sever emotion dysregulation was associated with higher risk of NSSI [29]. An anonymous, American student survey ( $n=1243$; mean age $21.5, \mathrm{SD}=4.2$ years $)$ found that $15 \%$ engaged in NSSI and $43 \%$ of those stated 'coping with uncomfortable feelings' as the reason for initiating this behaviour [26]. Compared to social motives, the survey participants endorsed emotion regulation as the most common reason for NSSI and repeating this.

The mentioned extensive hidden numbers may be related to the aspects of disclosing self-injurious behaviour to peers, parents, or health care providers [30]. The student survey found that $59 \%$ of their study population had disclosed their self-injurious behaviour to relatives or health professionals with the experience that this was not helpful [26]. Lack of knowledge and the inability to cope with children's negative emotions are associated with the perceived unhelpfulness of NSSI disclosure [26]. A need for social support may direct NSSI engaging youth towards peers. However, young people greatly influence each other, and it has been found that NSSI can be both initiated and maintained by social and environmental factors. This influence within groups has been observed in community samples [31] as well as inpatient populations [32, 33]. Therefore, it is important to intervene and to investigate up-stream and low-cost prevention strategies [34] preferably without elements of group therapy. Evidence-based interventions for NSSI specifically are sparse [35]. Evidence may support cognitive behavioural therapy (CBT) for adult individuals engaging in repetitive NSSI; however, the randomised clinical trials are with high uncertainty and the effects only moderate [36]. Internet-based solutions are assumed to be appealing to young people with maladaptive behaviours due to experiences of stigmatization [30]. A systematic review and meta-analysis investigating the effect of internet-delivered cognitive behavioural therapy (ICBT) for children and adolescents with a variety of psychiatric $(k=11)$ as well as somatic $(k$ $=14$ ) conditions (24 studies, $N=1882$ ) found moderate effect sizes in favour of ICBT compared with waitlist control in between group analysis (Hedge's $g=0.62,95 \%$ confidence interval (CI) 0.41 to 0.84 ) on a range of study-specific outcomes; however, study quality and ICBT content varied greatly across studies. Moreover, waitlist control may not be an adequate comparison condition to establish efficacy [37]. The pooled effect size for the ICBT interventions targeting the psychiatric conditions separately was $(k=11, N=473 ; g=1.27,95 \% \mathrm{CI}$ 0.96 to 1.59) [38] leaving online interventions to be further explored. 
Emotion regulation individual therapy for adolescents (ERITA) has been developed to meet the need for shortterm, effective and easily accessible treatment [39]. The therapeutic framework of ERITA encounters elements of emotion regulation group therapy (ERGT), cognitive behavioural therapy $(\mathrm{CBT})$, dialectical behavioural therapy (DBT) and acceptance and commitment therapy (ACT) [40]. An uncontrolled feasibility study of individual face-to-face ERITA provided to adolescents engaging in NSSI $(N=17)$, which was conducted in Sweden suggested improved emotion regulations skills and significantly reduced past month NSSI frequency [40]. Further research from the same research group replicated their findings in a subsequent feasibility study investigating an internet-based version of ERITA $(N=25)$ [41]. In addition to the adolescent intervention, both feasibility studies included a parent intervention to increase the understanding of NSSI and to improve coping skills with the children's negative emotions [41].

There is a need for replication of feasibility studies outside Sweden as well as randomised clinical trials testing specialised intervention for NSSI in this youth friendly format [38]. Before conducting larger pragmatic trials, we want to investigate the feasibility of ERITA in Denmark.

\section{Objective}

The objective of this feasibility trial is to assess the feasibility of methods, procedures, and safety of internetbased ERITA in a Danish context. We compare ERITA as an add-on to treatment as usual (TAU) versus TAU alone in 13-17-year-old patients with NSSI referred to psychiatric services in the Capital Region of Denmark.

\section{Hypotheses}

The primary hypotheses regarding feasibility are:

1. We expect $\geq 87 \%$ to complete follow-up questionnaires (data completion fraction at end of intervention).

2. We expect $\geq 40 \%$ of eligible patients and parents will be included by giving informed consent and proceed to randomisation.

3. We expect $\geq 73 \%$ of the participants will comply with experimental intervention and complete at least six modules out of 12 including an introduction.

4. We expect $\geq 73 \%$ of the participants' parents will comply with experimental intervention and complete at least three out of six modules.

\section{Methods/Design}

\section{Design}

A randomised, parallel group, feasibility trial with blinded outcome assessment at end of the intervention.

\section{Study setting}

Adolescents $(N=30 ; 13-17$ years both inclusive) with recurrent NSSI referred to outpatient clinics in Child and Adolescent Mental Health Services (CAMHS) in the Capital Region of Denmark. We wish to include a representative sample of patients with a variety of diagnoses since all may present with comorbidity of NSSI.

\section{Inclusion criteria}

- $\geq 5$ non-suicidal self-injury episodes during the past year and $\geq 1$ non-suicidal self-injury episodes during the past month assessed by the Deliberate SelfHarm Inventory, Youth version (DSHI-Y) [42].

- Age-appropriate Danish literacy assessed by referring clinicians and the self-injury team.

- At least one parent committing to participate in the parent program.

- Informed consent from parents/legal caretakers.

- Informed consent from the participant above 15 years of age.

\section{Exclusion criteria}

- Elevated or imminent suicidal risk assessed by clinicians during routine screening procedure (that can be rated as no risk, elevated risk, or imminent risk) in need of admission or other life saving strategies.

- Lack of informed consent from parents/legal caretakers.

- Lack of informed consent from the participant above 15 years of age.

\section{Informed consent for trial participation}

Detailed trial description and informed consent forms will be sent electronically to eligible participants and their parents linking personal ID numbers to secure mailbox. During the baseline interview after further assessment of eligibility, the clinicians will ask participants (adolescents $>15$ years of age and both custody holders) to give informed consent by accessing this secure link and signing. Consents and assents will be stored directly in the research database, REDCap.

\section{Treatment as usual}

Both the experimental group and the control group will receive TAU in CAMHS. TAU encounters a variety of clinical treatment and assessment offers, representing a highly inhomogeneous group of treatments, for instance: pharmacological treatment, family-based treatment, cognitive behavioural therapy, supportive counselling, and psychoeducation. Throughout the trial, the treatment 
responsibility is handled by clinicians providing TAU in CAMHS. In a subsequent large-scale trial, we expect TAU to be delivered equally in both arms and patients record data documented electronically, including treatment provision and duration will be obtained. Routine screening for suicidal behaviour is a part of the standard clinical assessment and treatment in CAMHS including safety screening and planning.

\section{ERITA}

The ERITA intervention [40, 41] as add-on to TAU is a manualised internet-based therapy based on emotion regulation group therapy, cognitive behavioural therapy, dialectical behavioural therapy and acceptance and commitment therapy. The program consists of an introduction plus 11 modules ranging in content from psychoeducation, through emotional awareness training, and regulation of impulses and emotions by acceptance and validation (Table 1). The intervention also provides six modules for the parents focusing on NSSI and other risk-taking behaviours, emotional awareness, and validation skills (Table 1 ).

ERITA is provided online and therapist-guided. The participants are expected to complete one module every week whilst the parents are expected to complete a module every second week. A mobile app is available to complement the online treatment. The app includes reminders of homework and skills and allows to report on both self-destructive behaviours and impulses daily. Weekly, electronically assessments of emotion regulation skills, NSSI, and potential risk behaviours will serve as intervention indicators for the therapist to guide the young ERITA participant during the intervention process. This intervention also includes a parent program with six modules focusing on psychoeducation and validations skills. The parents can review the adolescents' chapters each week, but not the correspondence between the adolescents and the therapist. In contrary to previous evaluations of ERITA [40, 41], the parent part of ERITA is not therapist guided in the current trial.

\section{Strategy to improve adherence to intervention}

If a participant fails to follow the treatment course by not accessing the web portal or by not replying to therapists' messages, the intervention team will assertively reach out by phone to both the patient and the parents. It is expected that major parts of the dialogue with participants constitute motivation to adhere to the ERITA.

\section{Staff, qualification, and training}

The staff in the self-injury team consists of psychologists and nurses, recruited with priority on experience within clinical child and adolescent psychiatry and with psychotherapy and special knowledge about NSSI. The staff is trained in the ERITA-manual [39] and will continually be supervised in the internet-based methods by clinicians and researchers of the Swedish National SelfInjury Project alongside Danish experts in the field. The self-injury team will warrant for the recruitment strategy by a continuous dialogue and update of staff in CAMHS.

\section{Outcomes \\ Feasibility outcomes are listed in order of importance}

\section{Completion of follow-up}

Completion of follow-up will be defined as completing assessment of at least one clinical outcome (NSSI events) at end of intervention. If the number participants with completed outcomes is 26 out of 30, the fraction will be $87 \%$, 95\% confidence interval (CI) $75 \%$ to $99 \%$. A

Table 1 An overview of the content of internet based ERITA

\begin{tabular}{|c|c|}
\hline Adolescent intervention (module content) & Parent program (module content) \\
\hline (1) Functions of non-suicidal self-injury & (1) Psychoeducation \\
\hline \multicolumn{2}{|l|}{ (2) Impulse control } \\
\hline (3) Functionality of emotions and emotional awareness & (2) Emotional awareness \\
\hline \multicolumn{2}{|l|}{ (4) Primary vs. secondary emotions } \\
\hline (5) Emotional avoidance / unwillingness vs. emotional acceptance / willingness & (3) Validation and invalidation \\
\hline \multicolumn{2}{|l|}{ (6) Non-avoidant emotion regulation strategies } \\
\hline $\begin{array}{l}\text { (7) Implementing emotional approach and non-avoidant emotion regulation } \\
\text { strategies }\end{array}$ & (4) Self-validation and self-invalidation \\
\hline \multicolumn{2}{|l|}{ (8) Validation and emotional approach } \\
\hline (9) Valued direction & $\begin{array}{l}\text { (5) How to improve parenting in the long run / behavioral } \\
\text { activation }\end{array}$ \\
\hline \multicolumn{2}{|l|}{ (10) Repetition } \\
\hline (11) Relapse prevention & (6) Summary and evaluation \\
\hline
\end{tabular}


follow-up fraction of $75 \%$ or more will be acceptable for a future trial whilst a fraction below $75 \%$ will impose serious problems of interpreting the trial result in a future large pragmatic trial.

2. The fraction of participants assessed for eligibility who consent to inclusion and randomisation

We will determine the fraction of potential participants as the number of eligible persons compared to the number of randomised persons. If the number of participants randomised out of the number of eligible persons is 30 out of 75 , the fraction will be $40 \%, 95 \%$ CI $29 \%$ to $51 \%$. A randomisation fraction of $29 \%$ or more will be acceptable for a future trial, whilst a fraction below $29 \%$ will impose serious problems of recruitment for a future large pragmatic trial.

\section{Compliance-adolescents}

Compliance with the experimental intervention will be defined as completing at least 6/11 ERITA sessions. The treatment platform will automatically register time for login and save the exercises that have been completed. If the number of compliant experimental participants is 11 out of 15 , the fraction will be $73 \%, 95 \%$ CI $51 \%$ to $96 \%$. A compliance fraction of $51 \%$ or more will be acceptable for a future trial whilst a fraction below $51 \%$ will impose serious problems of interpreting the trial result in a future large pragmatic trial.

\section{Compliance-parents}

Compliance with the experimental intervention will be defined as completing at least 3/6 ERITA sessions. The treatment platform will automatically register time for login and save the exercises that have been completed. If the number of compliant experimental participants is 11 out of 15 , the fraction will be $73 \%, 95 \%$ CI $51 \%$ to $96 \%$. A compliance fraction of $51 \%$ or more will be acceptable for a future trial whilst a fraction below $51 \%$ will impose serious problems of interpreting the trial result in a future large pragmatic trial.

\section{Clinical outcomes}

We will assess participants at the baseline interview and at the end of the intervention at 12 weeks after randomisation. The clinical outcomes are planned for a future pragmatic randomised trial, and these will only be investigated in an exploratory manner in this feasibility trial.

\section{Exploratory primary clinical outcome}

- NSSI, assessed at end of intervention (12 weeks) by blinded outcome assessment by video conference or phone with DSHI-Y, continuous outcome [42].

\section{Exploratory secondary clinical outcomes}

- Quality of life at 12 weeks, assessed with HealthRelated Quality of Life Questionnaire (Kidscreen-10) [43].

- Symptoms of depression, anxiety and stress at 12 weeks, assessed with Depression Anxiety Stress Scale (DASS-21) [44].

- Number of sick days the last month, assessed at 12 weeks.

\section{Further exploratory clinical outcomes}

- The proportion of participants with no NSSI during the last 4 weeks, assessed at 12 weeks follow-up (end of intervention).

- Difficulties in emotion regulation, assessed weekly during 12 weeks with Difficulties in Emotion Regulation Scale-16 Item Version (DERS-16) [45].

- Indirect self-destructive behaviours at 12 weeks, assessed with Borderline Symptom List (BSL-supplement) [46].

- Suicidal ideations, plans, and actions at 12 weeks, assessed with Columbia Suicide Rating Scale (CSSRS) [47].

- Adolescent rated parents' ability to cope with children's negative emotions at 6 weeks and 12 weeks, assessed with The Coping with Children's Negative Emotions Scale (CCNES-APP) [48].

- Parent-rated perceived ability to cope with children's negative emotions at 6 weeks and 12 weeks, assessed with The Coping with Children's Negative Emotions Scale Adolescent (CCNES-A) [48].

- Adverse Events of therapy at 12 weeks assessed with Negative Effects Questionnaire (NEQ) [49].

- Strengths and difficulties assessed by Strengths and difficulties questionnaire (SDQ) assessed at end of intervention [50].

- Working alliance with online therapist at 4 and 8 weeks, assessed with Working Alliance Inventory, short version (WAI-SR) [51].

\section{Participant safety}

TAU

Throughout the trial, the treatment responsibility is handled by clinicians providing TAU, including continuous risk assessment of suicidal behaviour as a part of routine clinical procedures and documentation. Patients receiving treatment in CAMHS and their families are instructed to attend the Child and Adolescent Mental Health Services emergency department in case of imminent suicidal risk. All families are carefully instructed on safety routines within the trial; hence, it is 
firmly stated in the participants' instructions that therapists are only available during working hours. In case of imminent risk and no contact can be made, the intervention team will notify the clinical staff providing TAU and hereby ensure further acute clinical psychiatric assessment.

\section{ERITA}

As a part of the provision of ERITA, participants in the experimental arm will weekly fill out electronic questionnaires on emotion regulation and potential risk behaviour such as alcohol drinking or substance misuse as well as suicidal behaviour. The weekly assessments serve two purposes: firstly, to provide the ERITA therapists with data on NSSI and emotion regulation skills as a part of the provision of the intervention. Secondly, because internet-based interventions have not previously been applied in CAMHS, these weekly assessments ensure participant safety and facilitate detection of sudden deterioration of participants, including suicidal ideation. An individualised crisis plan will be established prior to treatment start, which will contain necessary contact information to acute health care services. If the patient during the research course is assessed to be at increased suicidal risk, a notification in the program will alert all team members and a therapist will contact both the patient and the parents next working day.

\section{Diagnostic assessments and outcome measures Patient record data}

Both the baseline and 12-week follow-up interviews are held virtually in secure meeting fora. Data obtained manually during the interviews are entered in an electronic research data base right after the interviews. None of the interviews are audio or video taped. The baseline interview is scheduled to take $2.5 \mathrm{~h}$ whilst the follow-up interview will take about $30 \mathrm{~min}$. To minimise the baseline interview and assessment program, diagnosis codes will be obtained from patient records as a part of general clinical procedures. Also, data on the provision of TAU (treatment and length) for all participants will be obtained from the patients records by the end of treatment (12 weeks). Information on explorative outcomes and sick days the last 4 weeks will be obtained as selfreported at both baseline and follow-up by electronic questionnaires (Fig. 1).

\section{Intervention data}

During the internet-based intervention, data in the form of text as a part of the therapy will be provided; homework assignments will be presented, and therapists will write and interact with the participants, accordingly. The correspondence and interaction with participants and parents will differ in content according to individual needs but is expected to contain information on issues related to self-injury and coping strategies. Resource monitoring: we expect much of the therapeutic effort to focus on motivation to comply with modules and homework assignments. However, we do not yet know to what extent additional contact or support such as telephone calls or additional initiatives (e.g. emergency interventions) are required by the self-injury team.

\section{Technical issues}

A systematic monitoring of technical obstacles will be applied: login failures, forgotten passwords, inability to proceed during assignments or tasks, inability to hear audios or videos, and other unforeseen issues. All platform appearance will be monitored in detail including the need for web support. If technical issues appear or

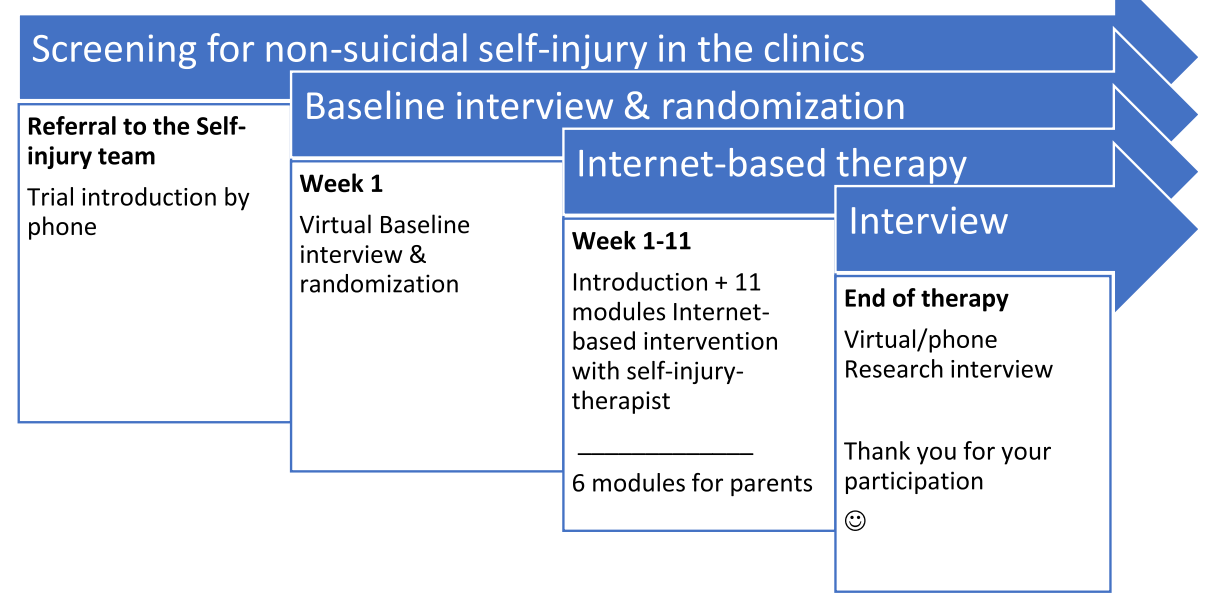

Fig. 1 Participant timeline 
implementation as well as completion of the online intervention (misunderstanding of modules or assignments) then adjustments will be considered in dialogue with the developers to ensure the internal validity in future large-scale trials.

\section{Resource allocation}

A systematic monitoring of additional resources such as crisis phone calls, calls to treatment provider in TAU, parents' consultations or rescheduling of baseline appointments will take place.

\section{Sample size and power considerations}

In this feasibility trial, we will include 30 participants corresponding to less than $10 \%$ of the probable sample size needed in a pragmatic large-scale trial. This corresponds to a power of $18 \%$ for the primary clinical outcome (self-injury episodes) in this trial, indicating that any positive result is purely exploratory and could be due to random error.

\section{Analysis, randomisation, and blinding}

The randomisation procedure will be provided by The Copenhagen Trial Unit (CTU) and be web-based. The allocation sequence will be computer-generated using block sizes of varying length concealed for the investigators. The allocation ratio is $1: 1$ and is blinded to the investigators.

Baseline characteristics will be assessed using descriptive statistics. The clinical exploratory outcomes will be analysed according to the principle of an intention-totreat approach. In a subsequent large-scale trial, missing data will be accounted for by multiple imputations if data are missing at random. All data on participants will be analysed independently of adherence to treatment. We will analyse data using logistic regression for dichotomous outcomes and linear regression for continuous outcomes. Due to the nature of the intervention, a blinding of participants and therapists is not possible. Blinded outcome assessment will be performed. Statistical analyses will be performed by two blinded statisticians presenting independent reports. Based on the two blinded conclusions, two abstracts will be written and published (on a website).

\section{Discussion \\ Design}

The TEENS feasibility trial is the second in Scandinavia to investigate the feasibility of methods in a randomised design [52]. The acceptance and feasibility of the ERITA intervention has previously been investigated in Sweden in observational designs [40]. The feasibility outcomes in the TEENS trial are (1) the completion rate of at least one questionnaire at 12 weeks follow-up, the most important outcome; (2) the fraction of eligible patients randomised and included in the trial in order to implement a subsequent large-scale trial; and (3) the fraction of participants compliant with the intervention (six of eleven modules). We have estimated targets for the three feasibility outcomes and calculated corresponding confidence intervals. Each of the three targets can be argued to be either too optimistic or too pessimistic. Regarding the proportion of participants completing follow-up, it can be argued that any proportion less than $100 \%$ will be detrimental to any analysis. However, to accommodate the 'real-life' setting, we are also aware that it is not always possible to achieve a $100 \%$ follow-up. The assessment of the completion rate of at least one questionnaire at 12 weeks follow-up is essential in relation to the feasibility of a large-scale trial, where a high follow-up rate is important to potential effect sizes.

The TEENS feasibility trial will indicate if the recruitment strategy works. As a part of the implementation of the trial in CAMHS, a routine screening procedure for NSSI has been introduced to assess for inclusion criteria and eligibility. The efficacy of this screening procedure will be evaluated during the feasibility trial, as the number of referred patients followed by an assessment of eligibility and randomisation fraction.

The time frame of recruitment for the feasibility part is planned to 6 to 7 months (May-November 2020) which is assessed feasible. The randomisation procedure will also be tested, and the high-quality design will show if patients and their families want to participate in spite the risk of an allocation outcome not initially wished for. The feasibility part will also show if the parallel group design is accepted by the referring clinical staff. We expect the young patients to be tech-natives and with limited barriers to online activities and interventions. However, this feasibility trial will tell if the participants are motivated to comply with six out of eleven ERITA modules or if they are hard to engage during therapy.

\section{Internet-based treatment}

No specific treatment targeting NSSI is provided in mental health services in either in- or out-patients settings in Denmark. The TEENS feasibility trial aims to fill this gap by testing the feasibility of a novel internetbased treatment among youth with psychiatric disorders. Provision of internet-based therapy in general is sparse in Denmark and for the time being only provided in one out of five regions. Here, online treatment for depression and anxiety has been offered adult patients since 2015 [53]. The internet-based treatments are therapist guided, self-help programs based on cognitive behavioural therapy; however, none of these programs are offered to adolescents. The TEENS feasibility trial will investigate if online treatment is appealing and easy to access for 
psychiatric youth and first and foremost if no serious adverse effects are observed. It has previously been observed that NSSI engaging youth have a better therapeutic response to online interventions compared to suicidal young people [54]; such therapeutic response, assessed as working alliance, will be evaluated during this trial. The potential to expand online interventions for other diagnoses within child and adolescent psychiatry may depend on the acceptance, feasibility and security of the online intervention in this trial; hence, this trial may inform future interventions.

\section{Parent involvement}

This trial also includes a parent program with six modules focusing on psychoeducation and validations skills. Previous studies have found that an inability to cope with children's negative emotions as well as invalidating manners are (risk) factors associated with NSSI [23, 25, 26], thus the maladaptive behaviours may be rooted in a family dysfunction. It is important to learn if the parent part is supportive for the youth which will be assessed by the Coping with Children's Negative Emotions Scale for Adolescent rated by both the adolescent and the participating parent (CCNES-A, CCNES-APP) [48, 55].

\section{Strength and limitations}

The ultimate strength of this trial is the randomised design. It is a strength that all the implementation of the intervention platform is managed by the intervention team; translation into Danish, layout and performance of audios and videos are matched to a Danish context. Platform operation and the therapeutic content is well known to trained staff members. Also, the trial organisation and implementation on an administrative level is a strength. A NSSI screening procedure implemented in CAMHS may contribute to the motivation of clinicians referring patients to the trial. We do not expect the internet-based intervention to have any serious adverse effects; however, this will be monitored closely by NEQ at post intervention assessment and by weekly assessments of self-harming behaviours including suicidal behaviour.

It is not possible to blind the participants nor the therapists which may impose a risk of bias despite blinded outcome assessment at end of intervention. The estimates of the feasibility outcome on completion is based on a rate of $88 \%$ as post treatment assessment observed in a previous Swedish feasibility study [41]; however, our estimates of the other feasibility benchmarks may impose a limitation due to lack of comparable investigations. We have estimated targets for the three feasibility outcomes and calculated corresponding confidence intervals. However, each of the three targets can be argued to be either too optimistic or too pessimistic. Regarding the proportion of participants completing follow-up, it can be argued that any proportion less than $100 \%$ will be detrimental to any analysis. The enrollment proportion and the compliance proportion are chosen from a pragmatic point of view, from what we estimate to be the lowest feasible numbers when conducting a large-scale randomised trial.

Further, the low sample size of 30 participants leaves any further explorative findings open to a large risk of random error. The weekly electronic online assessment of emotion regulation, NSSI and other potential risk behaviours in the experimental arm exclusively may impose a risk of confounding, since this is an opportunity of additional crisis intervention from the self-injury team in case of flag alerts. A potential limitation of the trial could be the provision of TAU; the lack of an experimental component in the TAU arm only, may lead to extended provision of TAU efforts in both frequency and duration causing an unsound effect which may overshadow or compromise the effect of the experimental intervention. Also, we will opt out to adjust from TAU efforts in the statistical analyses, because they will be provided post randomisation [56, 57].

Online interventions in psychiatric youth populations are pioneer work which implies an area of uncertainty; however, this high-quality feasibility trial with the recruitment and treatment responsibility held by mental health services secure both patient safety as well as outcome estimates in less risk of bias.

\section{Conclusions}

The TEENS feasibility trial is important in several ways. Firstly, it provides feasibility assessment in a randomised design. Secondly, we investigate an intervention specifically developed to address NSSI by teaching and implementation of emotion regulations as well as validations skills in self-injuring youth and their parent. Thirdly, this is the first-time child and adolescent's health care services provide internet-based therapy in Denmark; an opportunity to be further explored, potentially within other kinds of psychopathology such as for anxiety and depression. If the online intervention in the TEENS trial is accepted and completed among NSSI patients with no risk of side effects, then this may be extended to other groups of NSSI engaging youth, thus used as a potential up-stream prevention strategy.

\section{Trial status}

Recruitment began mid-May 2020, and we expect the last participant to be included in November 2020.

\section{Abbreviations}

NSSI: Non-suicidal self-injury; ERITA: Emotion regulation internet-based therapy for adolescents; CBT: Cognitive behavioural therapy; ICBT: Internet-

delivered cognitive behavioural therapy; $g$ : Hedge's $g$; $n$ : Number of included 
participants; ERGT: Emotion regulation group therapy; DBT: Dialectical behavioural therapy; ACT: Acceptance and commitment therapy; CAMH S: Child and Adolescent Mental Health Services; DSM-5: Diagnostic and Statistical Manual of Mental Disorders, Fifth Edition; REDCap: Research data base; CTU: The Copenhagen Trial Unit; Kidscreen-10: Health-Related Quality of Life Questionnaire; DASS-21: Depression Anxiety Stress Scale; DERS16: Difficulties in Emotion Regulation Scale-16 item version; BSLsupplement: Borderline Symptom List; C-SSRS: Columbia Suicide Rating Scale; CCNES-APP: The Coping with Children's Negative Emotions Scale; CCNESA: The Coping with Children's Negative Emotions Scale Adolescent; NEQ: Negative Effects Questionnaire; SDQ: Strengths and Difficulties Questionnaire; WAI-SR: Working Alliance Inventory, short version

\section{Acknowledgements}

We would like to acknowledge all the participating adolescents and their parents. Moreover, we would like to thank PhD student Olivia Simonsson In the Swedish National Self-injury project for the training in the ERITA intervention as well as for being available for clarifying questions in the provision of ERITA from a research perspective.

\section{Authors' contributions}

$B M, L R$ and BRM obtained public funding for the Self-injury team and a post doc scholarship. BM, LR, BRM, JB and CH collaborated on the translation of ERITA manual and platform from Swedish into Danish. The trial was designed by all authors who have also prepared and accepted the manuscript. JL, JCJ, and CG as CTU trial specialists are vouching for statistical analyses. The authors read and approved the final manuscript.

\section{Funding}

Funding was provided by Mental Health Services in the Capital Region of Denmark for the post doc scholar ship (Journal number: 19065370/ D6283554) and the Rate Adjustment pool 2019-2012 for the intervention team (Danish National Board of Health, file number: 4-1613-252-5), hence funding from public and governmental agencies. Funders had no role in study design, data collection and analysis, decision to publish, or preparation of the manuscript.

\section{Availability of data and materials}

The trial investigators, selected members of the steering committee experts in the research database (BASS4) and investigators and statisticians at The Copenhagen Trial Unit will have access to the data. The datasets generated and analysed during this trial will not be made public available due to Danish law of data protection; however, a depersonalised final dataset will be sought to be made publicly available after publication of the trial results at The Danish National Archives (Rigsarkivet) as permitted by the Danish Data protection Agency.

\section{Ethics approval and consent to participate}

The trial notified the Regional Ethics Committee for the Capital Region, who assessed it as 'no need of approval' (H-19042904 TEENS-Trial) and the Data protection Agency (reference id.: P-2020-113, Pactius). The trial is registered ClinicalTrials.gov Identifier: NCT04243603. Written, informed consent to participate will be obtained from all participants and their parents or guardians.

\section{Consent for publication}

Not applicable.

\section{Competing interests}

The authors declare that they have no competing interests.

\footnotetext{
Author details

${ }^{1}$ Research Unit, Child and Adolescent Mental Health Services, The Capital Region of Denmark, Gentofte Hospitalsvej 15, 2900 Hellerup, Denmark. ${ }^{2}$ Team of Self-Injury, Child and Adolescent Mental Health Services, The Capital Region of Denmark, Lersøpark allé 107, 2100 Copenhagen Ø, Denmark. ${ }^{3}$ Copenhagen Trial Unit, Centre for Clinical Intervention Research, Rigshospitalet, Blegdamsvej 9, 2100 Copenhagen $\varnothing$, Denmark. ${ }^{4}$ Department of Regional Health Research, The Faculty of Health Sciences, University of Southern Denmark, Odense, Denmark. ${ }^{5}$ Centre for Psychiatry Research, Department of Clinical Neuroscience, Karolinska Institutet, \& Stockholm Health Care Services, Stockholm County Council, Stockholms läns
}

sjukvårdsområde (SLSO), Sachsgatan 10, 11861 Stockholm, Sweden. ${ }^{6}$ Department of Communication and Psychology, Aalborg University, Teglgårds Plads 1 (Nordkraft), 9200 Aalborg, Denmark.

Received: 2 December 2020 Accepted: 29 January 2021

Published online: 06 February 2021

\section{References}

1. Jacobson CM, Gould M. The epidemiology and phenomenology of nonsuicidal self-injurious behavior among adolescents: a critical review of the literature. Arch Suicide Res. 2007:11(2):129-47.

2. Muehlenkamp JJ, Claes L, Havertape L, Plener PL. International prevalence of adolescent non-suicidal self-injury and deliberate self-harm. Child Adolesc Psychiatry Ment Health. 2012;6:10.

3. Swannell SV, Martin GE, Page A, Hasking P, St John NJ. Prevalence of nonsuicidal self-injury in nonclinical samples: systematic review, metaanalysis and meta-regression. Suicide Life Threat Behav. 2014;44(3):273-303.

4. Geulayov G, Casey D, McDonald KC, Foster P, Pritchard K, Wells C, et al. Incidence of suicide, hospital-presenting non-fatal self-harm, and community-occurring non-fatal self-harm in adolescents in England (the iceberg model of self-harm): a retrospective study. Lancet Psychiatry. 2018; 5(2):167-74.

5. Zetterqvist M, Lundh LG, Dahlstrom O, Svedin CG. Prevalence and function of non-suicidal self-injury (NSSI) in a community sample of adolescents, using suggested DSM-5 criteria for a potential NSSI disorder. J Abnorm Child Psychol. 2013:41(5):759-73.

6. Whitlock J, Muehlenkamp J, Purington A, Eckenrode J, Barreira P, Baral Abrams G, et al. Nonsuicidal self-injury in a college population: general trends and sex differences. J Am Coll Health. 2011;59(8):691-8.

7. Plener PL, Schumacher TS, Munz LM, Groschwitz RC. The longitudinal course of non-suicidal self-injury and deliberate self-harm: a systematic review of the literature. Borderline Personal Disord Emot Dysregul. 2015;2:2.

8. Andrewes HE, Hulbert C, Cotton SM, Betts J, Chanen AM. Relationships between the frequency and severity of non-suicidal self-injury and suicide attempts in youth with borderline personality disorder. Early Interv Psychiatry. 2019;13(2):194-201.

9. Zanarini MC, Frankenburg FR, Reich DB, Fitzmaurice G, Weinberg I, Gunderson JG. The 10-year course of physically self-destructive acts reported by borderline patients and axis II comparison subjects. Acta Psychiatrica Scand. 2008;117(3):177-84.

10. Fox KR, Franklin JC, Ribeiro JD, Kleiman EM, Bentley KH, Nock MK. Metaanalysis of risk factors for nonsuicidal self-injury. Clin Psychol Rev. 2015;42: 156-67.

11. Batejan KL, Jarvi SM, Swenson LP. Sexual orientation and non-suicidal selfinjury: a meta-analytic review. Arch Suicide Res. 2015;19(2):131-50.

12. van Geel M, Goemans A, Vedder P. A meta-analysis on the relation between peer victimization and adolescent non-suicidal self-injury. Psychiatry Res. 2015:230(2):364-8

13. Taliaferro LA, Muehlenkamp JJ. Factors associated with current versus lifetime self-injury among high school and college students. Suicide Life Threat Behav. 2015;45(1):84-97.

14. Bresin K, Schoenleber M. Gender differences in the prevalence of nonsuicidal self-injury: A meta-analysis. Clin Psychol Rev. 2015;38:55-64.

15. Bjureberg J, Ohlis A, Ljótsson B, D'Onofrio BM, Hedman-Lagerlöf E, Jokinen J, et al. Adolescent self-harm with and without suicidality: cross-sectional and longitudinal analyses of a Swedish regional register. J Child Psychol Psychiatry. 2019;60(3):295-304.

16. Ohlis A, Bjureberg J, Lichtenstein $P$, D'Onofrio BM, Fruzzetti $A E$, Cederlöf $M$, et al. Comparison of suicide risk and other outcomes among boys and girls who self-harm. Eur Child Adolesc Psychiatry. 2020;29:1-6.

17. Muehlenkamp JJ, Gutierrez PM. Risk for suicide attempts among adolescents who engage in non-suicidal self-injury. Arch Suicide Res. 2007; 11(1):69-82.

18. Muehlenkamp JJ, Brausch AM. Protective factors do not moderate risk for past-year suicide attempts conferred by recent NSSI. J Affect Disord. 2019; 245:321-4.

19. Wilkinson P, Kelvin R, Roberts C, Dubicka B, Goodyer I. Clinical and psychosocial predictors of suicide attempts and nonsuicidal self-injury in the Adolescent Depression Antidepressants and Psychotherapy Trial (ADAP T). Am J Psychiatry. 2011;168(5):495-501. 
20. Nock MK, Kessler RC. Prevalence of and risk factors for suicide attempts versus suicide gestures: analysis of the National Comorbidity Survey. J Abnorm Psychol. 2006;115(3):616-23.

21. Whitlock J, Muehlenkamp J, Eckenrode J, Purington A, Baral Abrams G, Barreira $\mathrm{P}$, et al. Nonsuicidal self-injury as a gateway to suicide in young adults. J Adolesc Health. 2013;52(4):486-92.

22. Nock MK. Why Do People Hurt Themselves?:New Insights into the nature and functions of self-injury. Curr Direct Psychol Sci. 2009;18(2):78-83.

23. Armiento J, Hamza CA, Stewart SL, Leschied A. Direct and indirect forms of childhood maltreatment and nonsuicidal self-injury among clinicallyreferred children and youth. J Affect Disord. 2016;200:212-7.

24. Liu RT, Scopelliti KM, Pittman SK, Zamora AS. Childhood maltreatment and non-suicidal self-injury: a systematic review and meta-analysis. Lancet Psychiatry. 2018;5(1):51-64.

25. Glassman LH, Weierich MR, Hooley JM, Deliberto TL, Nock MK. Child maltreatment, non-suicidal self-injury, and the mediating role of selfcriticism. Behav Res Ther. 2007:45(10):2483-90.

26. Muehlenkamp J, Brausch A, Quigley K, Whitlock J. Interpersonal features and functions of nonsuicidal self-injury. Suicide Life Threat Behav. 2013;43(1):6780.

27. Nock MK, Prinstein MJ. A functional approach to the assessment of selfmutilative behavior. J Consult Clin Psychol. 2004;72(5):885-90.

28. Taylor PJ, Jomar K, Dhingra K, Forrester R, Shahmalak U, Dickson JM. A meta-analysis of the prevalence of different functions of non-suicidal selfinjury. J Affect Disord. 2018:227:759-69.

29. Wolff JC, Thompson E, Thomas SA, Nesi J, Bettis AH, Ransford B, et al. Emotion dysregulation and non-suicidal self-injury: a systematic review and meta-analysis. Eur Psychiatry. 2019;59:25-36.

30. Armiento JS, Hamza CA, Willoughby T. An Examination of Disclosure of Nonsuicidal Self-injury among University Students. J Commun Appl Soc Psychol. 2014;24(6):518-33.

31. Schwartz-Mette RA, Lawrence HR. Peer socialization of non-suicidal selfinjury in adolescents' close friendships. J Abnorm Child Psychol. 2019:47(11): 1851-62.

32. Prinstein MJ, Heilbron N, Guerry JD, Franklin JC, Rancourt D, Simon V, et al. Peer influence and nonsuicidal self injury: longitudinal results in community and clinically-referred adolescent samples. J Abnorm Child Psychol. 2010; 38(5):669-82.

33. Jarvi $\mathrm{S}$, Jackson $B$, Swenson $L$, Crawford $H$. The impact of social contagion on non-suicidal self-injury: a review of the literature. Arch Suicide Res. 2013; 17(1):1-19.

34. Ougrin D, Tranah T, Stahl D, Moran P, Asarnow JR. Therapeutic interventions for suicide attempts and self-harm in adolescents: systematic review and meta-analysis. J Am Acad Child Adolesc Psychiatry. 2015;54(2):97-107.e2.

35. Turner BJ, Austin SB, Chapman AL. Treating nonsuicidal self-injury: a systematic review of psychological and pharmacological interventions. Can J Psychiatry. 2014;59(11):576-85.

36. Hawton K, Witt KG, Taylor Salisbury TL, Arensman E, Gunnell D, Townsend E, et al. Interventions for self-harm in children and adolescents. Cochrane Database Syst Rev. 2015;12:Cd012013.

37. Faltinsen E, Todorovac A, Hróbjartsson A, Gluud C, Kongerslev MT, Simonsen $E$, et al. Placebo, usual care and wait-list interventions for all mental health disorders. Cochrane Database Syst Rev. 2019;(1). https://doi.org/10.1002/14 651858.MR000050

38. Vigerland S, Lenhard F, Bonnert M, Lalouni M, Hedman E, Ahlen J, et al. Internet-delivered cognitive behavior therapy for children and adolescents: A systematic review and meta-analysis. Clin Psychol Rev. 2016;50:1-10.

39. Sahlin B. The ERITA Manual; BUP-kliniken. Stockholms läns sjukvårdsområde (SLSO), Sachsgatan; Stockholm. 2018.

40. Bjureberg J, Sahlin H, Hellner C, Hedman-Lagerlof E, Gratz KL, Bjarehed J, et al. Emotion regulation individual therapy for adolescents with nonsuicidal self-injury disorder: a feasibility study. BMC Psychiatry. 2017;17(1):411.

41. Bjureberg J, Sahlin H, Hedman-Lagerlöf E, Gratz KL, Tull MT, Jokinen J, et al. Extending research on emotion regulation individual therapy for adolescents (ERITA) with nonsuicidal self-injury disorder: open pilot trial and mediation analysis of a novel online version. BMC Psychiatry. 2018;18(1):326.

42. Gratz K. Measurement of deliberate self-harm: preliminary data on the Deliberate Self-Harm Inventory. J Psychopathol Behav Assess. 2001;23:253-63.

43. Ravens-Sieberer U, Erhart M, Rajmil L, Herdman M, Auquier P, Bruil J, et al. Reliability, construct and criterion validity of the KIDSCREEN-10 score: a short measure for children and adolescents' well-being and health-related quality of life. Qual Life Res. 2010;19(10):1487-500.

44. Henry JD, Crawford JR. The short-form version of the Depression Anxiety Stress Scales (DASS-21): Construct validity and normative data in a large non-clinical sample. Brit J Clin Psychol. 2005;44(2):227-39.

45. Bjureberg J, Ljotsson B, Tull MT, Hedman E, Sahlin H, Lundh LG, et al. Development and validation of a brief version of the difficulties in emotion regulation scale: The DERS-16. J Psychopathol Behav Assess. 2016;38(2):28496.

46. Bohus M, Kleindienst $N$, Limberger MF, Stieglitz RD, Domsalla M, Chapman $A L$, et al. The short version of the borderline symptom List (BSL-23): Development and Initial Data on Psychometric Properties. Psychopathology. 2009:42(1):32-9.

47. Conway PM, Erlangsen A, Teasdale TW, Jakobsen IS, Larsen KJ. Predictive validity of the Columbia-Suicide Severity Rating Scale for short-term suicidal behavior: a Danish study of adolescents at a high risk of suicide. Arch Suicide Res. 2017;21(3):455-69.

48. Fabes RA, Poulin RE, Eisenberg N, Madden-Derdich DA. The coping with children's negative emotions scale (CCNES): psychometric properties and relations with children's emotional competence. Marriage Fam Rev. 2002; 34(3-4):285-310.

49. Rozental A, Kottorp A, Boettcher J, Andersson G, Carlbring P. Negative effects of psychological treatments: An exploratory factor analysis of the negative effects questionnaire for monitoring and reporting adverse and unwanted events. PLOS One. 2016;11(6):e0157503.

50. Muris $P$, Meesters $C$, van den Berg F. The strengths and difficulties questionnaire (SDQ). Eur Child Adolesc Psychiatry. 2003;12(1):1-8.

51. Hatcher RL, Gillaspy JA. Development and validation of a revised short version of the Working Alliance Inventory. Psychother Res. 2006;16(1):12-25.

52. Internet Delivered ERITA for Nonsuicidal Self-Injury (ERITA) Clinical Trials2017/2020 [Available from: https://clinicaltrials.gov/ct2/show/NCT03353 961. Accessed Jan 2021.

53. Syddanmark R. Internet terapi [Available from: http://www.internetpsykia trien.dk/wm507341. Accessed Dec 2020

54. Ougrin D, Zundel T, Kyriakopoulos M, Banarsee R, Stahl D, Taylor E. Adolescents with suicidal and nonsuicidal self-harm: clinical characteristics and response to therapeutic assessment. Psychol Assess. 2012;24(1):11-20.

55. Fabes RA, Leonard SA, Kupanoff K, Martin CL. Parental coping with children's negative emotions: relations with children's emotional and social responding. Child Dev. 2001;72(3):907-20.

56. Rochon J. Issues in adjusting for covariates arising postrandomization in clinical trials. Drug Inform J. 1999:33(4):1219-28.

57. Agency EM. Guideline on adjustment for baseline covariates in clinical trials 2015 Available from: https://www.ema.europa.eu/en/documents/scientificguideline/guideline-adjustment-baseline-covariates-clinical-trials_en.pdf.

\section{Publisher's Note}

Springer Nature remains neutral with regard to jurisdictional claims in published maps and institutional affiliations.

Ready to submit your research? Choose BMC and benefit from:

- fast, convenient online submission

- thorough peer review by experienced researchers in your field

- rapid publication on acceptance

- support for research data, including large and complex data types

- gold Open Access which fosters wider collaboration and increased citations

- maximum visibility for your research: over $100 \mathrm{M}$ website views per year

At $\mathrm{BMC}$, research is always in progress.

Learn more biomedcentral.com/submissions 